2006-2433: PRACTICING WHAT WE PREACH: WORK MEASUREMENT AND METHODS IMPROVEMENT FOR THE STEPS CAMP

Mary Kundrat, Grand Valley State University

Graduate Student in the Padnos School of Engineering at Grand Valley State University

Shabbir Choudhuri, Grand Valley State University 


\section{Practicing What We Preach: Work Measurement and Methods Improvement for the STEPS Camp}

\section{Introduction and Overview}

The global trend and high competition in the manufacturing arena are making it more imperative to deploy conventional and alternative process improvement tools. "Manufacturing Work Environments", a graduate course at Grand Valley State University (GVSU) addresses the issues related to work measurement, method improvement, safety, and ergonomic aspects in work design. As a practice oriented teaching school, GVSU highly emphasizes the culmination of the learning process by the realistic execution of the principles and techniques taught in a course. In that tradition, this course employed a semester ending project as an important tool to develop the proper understanding of the course materials.

This particular project idea involved improving the efficiency, performance and work environment at the Science, Technology, and Engineering Preview Summer (STEPS) camp held at Grand Valley State University. The STEPS camp at the university is intended to introduce seventh grade girls to the fields of engineering and technology. The primary and most important activity in the camp is the construction of model airplanes. Even though the STEPS camp is not a traditional manufacturing environment, there exist many parallelisms. Moreover, application of process improvement tools at non-traditional cases is not rare [1]. In addition to improving the efficiency of the camp, this project aims to teach the participants valuable industrial engineering principles by instilling good workplace practices. Incidental learning, especially among children, is a well recognized phenomenon $[2,3]$.

This project analyzed and improved the three major areas of the camp, namely Material Inventory and Consumption, Material Storage, and Airplane Construction. The complete work was submitted to the STEPS administrator at GVSU [4]. This paper presents selected applications of the industrial engineering (IE) principles only in the Airplane Construction portion of the STEPS camp.

\section{Airplane Construction}

Construction of the airplanes involves eighteen work stations located in three separate rooms. Initial studies revealed weaknesses that could be remedied by the application of standard IE tools. One of the major problems in the existing process is the flow among work stations within a particular room. Participants fail to understand the goal of a series of tasks because of the confusing work flow. Even within a workstation, lack of material organization causes physical discomfort, chaos, and reduced efficiency.

Though work-standard instructions for each station are provided in each room, the camp participants do not refer to them during the construction process. The time allotment for each construction room does not give the participants the opportunity to read through the details. Moreover, they were written in a traditional authoritative manner, failing to provide the 
ownership of the information [5] to the participants. In general, lack of communication hampers the overall performance, causes frustration, increases waste, and raises safety concerns.

\section{Application of IE Tools and Improvements}

Initial assessment showed that streamlining the airplane construction requires analysis and improvement of the individual work stations. Most of the stations are somewhat small and have a significant amount of materials associated with them. The analysis starts with the creation of process flow charts [6] for all eighteen stations. Each process is charted based on the primary activities performed at that station. The process flow chart for the Tail and Tail/Rudder Assembly Station is shown in Figure 1. The preliminary process flow charts did not show many redundant activities, but by relocating materials to more appropriate areas, many actions and movements were eliminated, reducing the time required to complete each station. All of the flow charts have been submitted for implementation in future camps. A total of 16 unnecessary activities were eliminated from the stations' activities by simple material relocation [1].

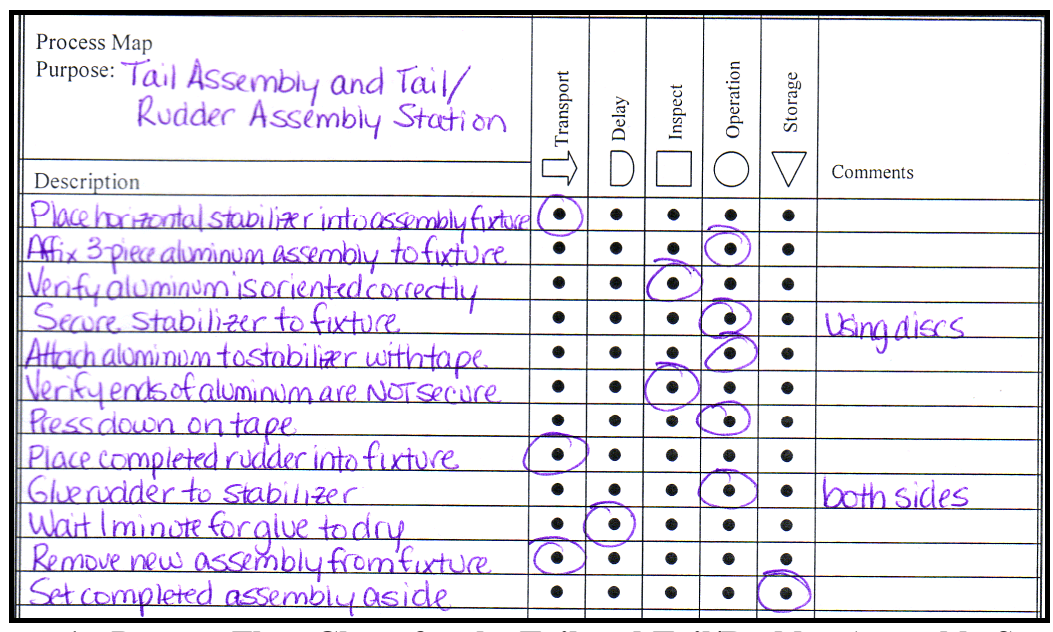

Figure 1: Process Flow Chart for the Tail and Tail/Rudder Assembly Station

Once the activities are finalized, principles of Motion Economy [7] were employed to improve the necessary tasks. The first rule of Motion Economy states that activities should be designed to deploy the lowest classification of basic motions whenever possible [8]. In order to achieve this, all material locations were analyzed and rearranged. For example, in the Canopy Trimming Station, the uncut canopies are located in a bin underneath the table. A participant must reach down, choose a canopy, stand back up and begin working. According to the Principles of Motion Economy, this action is deemed as a class V motion because it uses the fingers, wrist, lower arm, upper arm, shoulder and waist. This project's research proposed a new location for the canopies on top of the trimming station table. Hence, the motion will be reduced to a class III as it would only require the use of the fingers, wrist, and lower arm. The list of all such improvements and necessary relocations were submitted to the camp's director [1].

Another rule pertaining to the movements of the human body states that work should be designed so that the operator can use their preferred hand whenever possible [8]. To accommodate both left handed and right handed participants, materials are arranged centrally and made accessible 
from both sides of the stations. Moreover, necessary hand tools, such as right and left handed scissors are recommended.

It has been observed that many wasted and idle motions were due to the lack of locations for smaller items, such as rubber bands, scissors, and tape. Therefore, this research proposed labeled organizers or bins with multiple receptacles for smaller but commonly used items at each station. This will eliminate the confusion of locating a material when it is needed.

A further in depth analysis of the motions was done in light of ergonomics, specifically considering the reach of young workers [9]. It has been found that in many activities, participants have to reach across tables, walk around tables, and expend significant amounts of energy to accomplish the objectives of the station. For example, the Wing Section Assembly Station currently has the glue guns centrally located for easy access, but the glue sticks are at one end of the table. This is shown in Figure 2. It would be more appropriate to have the glue sticks located near the glue guns to prevent unnecessary motions such as walking around the table or overextending.

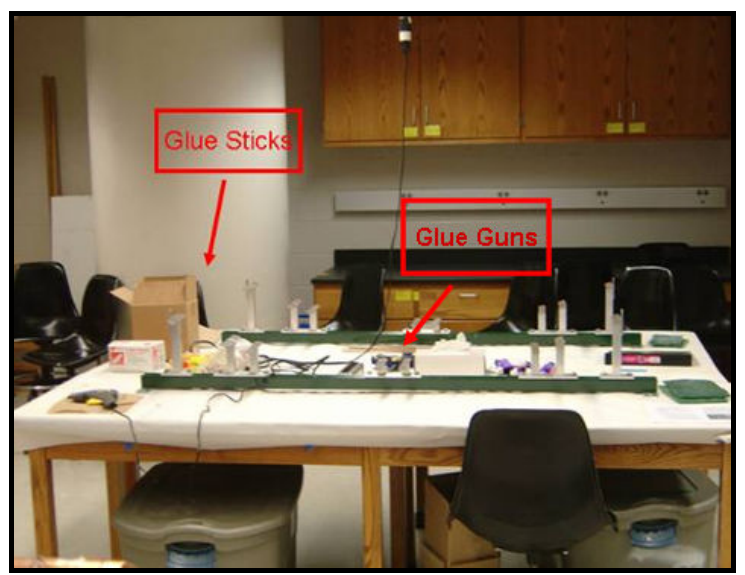

Figure 2: The Wing Section Assembly Station

The communication problem is addressed by the application of Visual Factory principles [5]. The improvements can be categorized in three different sectors. First, this project proposed visual aids to promote safety features rather than written orders. A set of safety signs, like the one shown in Figure 3 were proposed. 


\section{CAUTION!!!}

For your protection, safety goggles are REQUIRED at this Station!!
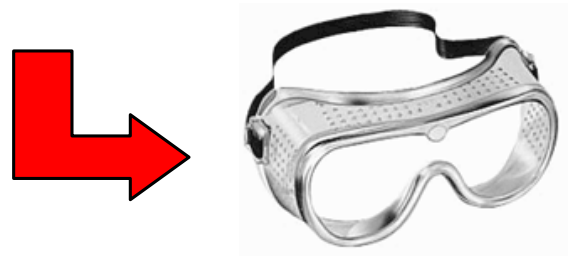

Figure 3: Example of a Safety Sign

Secondly, visual signs are proposed for each individual station to improve flow and clarify each station's purpose. The proposed signs consist of a number designating the relative position of the station with respect to the flow inside a room and an unambiguous name for the station relating to the station's objective. For example, Figure 4 shows the proposed sign for the first station in the Wing Room.

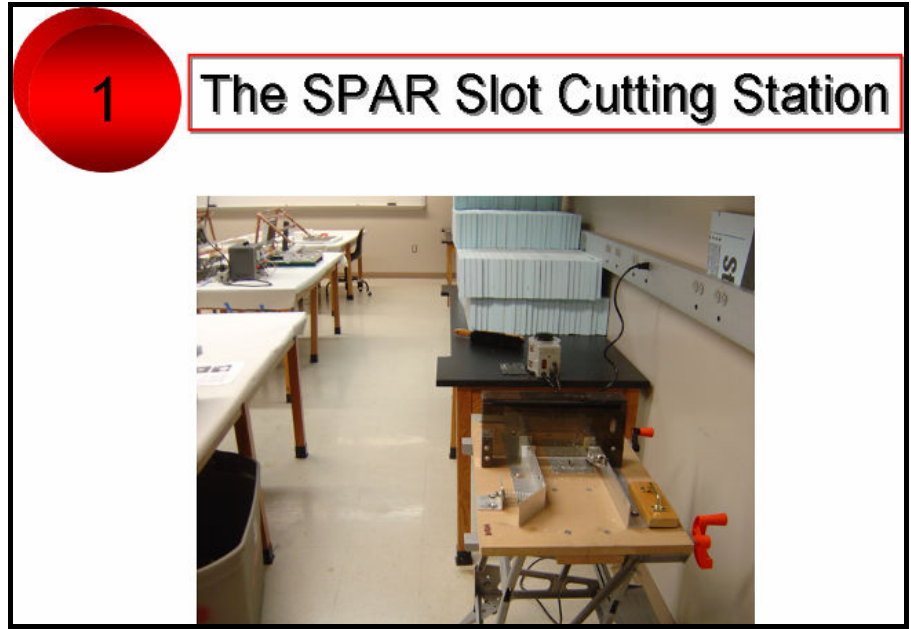

Figure 4: Visual Description Sign for a Station

In the third and final category of visual aides, this project designed pictural work instructions for each station. Although existing process plans are detailed and explicit, they require additional time to comprehend. The proposed pictural instructions will considerably lessen the learning time. It should be noted that the proposed signs are in addition to the existing process plans and are not meant to be a replacement. A good example would be the Nose Cone Molding Station. Reading the instructions provided by the process plans might not be sufficient to fully comprehend all the activities and the suitable end result. The addition of the pictural instructions as shown in Figure 5 will create a better understanding of the each activity in the station. 


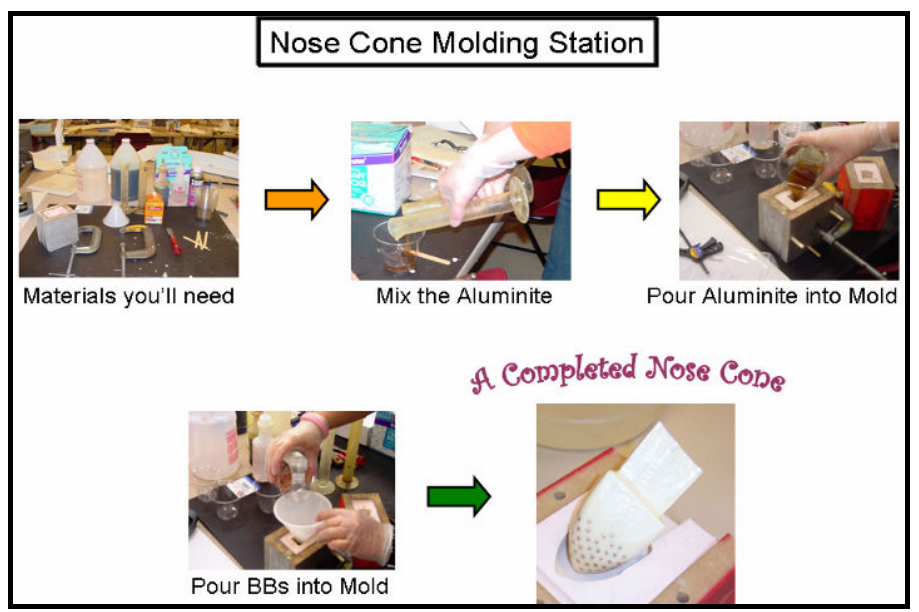

Figure 5: Implementation of Visual Factory at an Individual Station

Once the individual stations are improved, interrelated activities are grouped together and their corresponding stations are physically brought in closer proximity to each other, similar to cellular manufacturing. This will improve the understanding of the series of activities and make the entire experience more comprehensible.

Finally, in order to streamline the construction rooms existing flow diagrams [6] for each of the rooms are created. The flow diagrams revealed cross paths and complex patterns from station to station. After careful analysis and rearrangement of work stations, new flow diagrams for each construction room were developed. The flow diagrams readily depict the gain in efficiency and performance. As an example, the existing and proposed flow diagrams for the Wing Room are provided in Figures 6 and 7.

The Wing Room is by far the most complex of all three rooms. The equipment in this room is significantly larger than that of the other rooms, hence space is very important. There are currently seven separate stations in this room that are all dependent upon each other, requiring sequential completions of the activities in a particular order. The existing flow diagram for the original setup of the Wing Room is shown in Figure 6. 


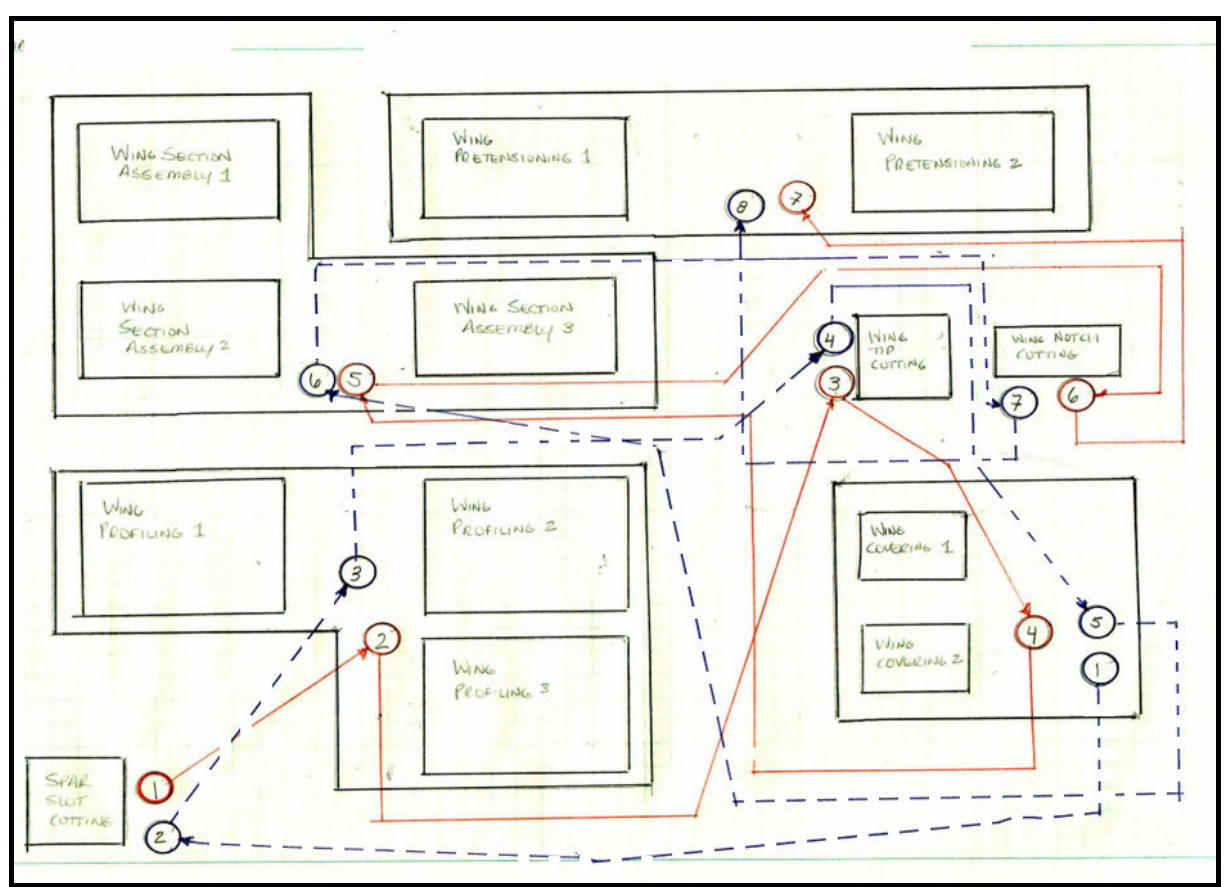

Figure 6: Current Wing Room Layout

As shown in the figure, the current arrangement permits two different paths through the seven work stations within the room. Unfortunately, the second path, depicted by the dashed line, requires two visits to the Wing Covering Station. A new flow diagram was developed and is presented in Figure 7.

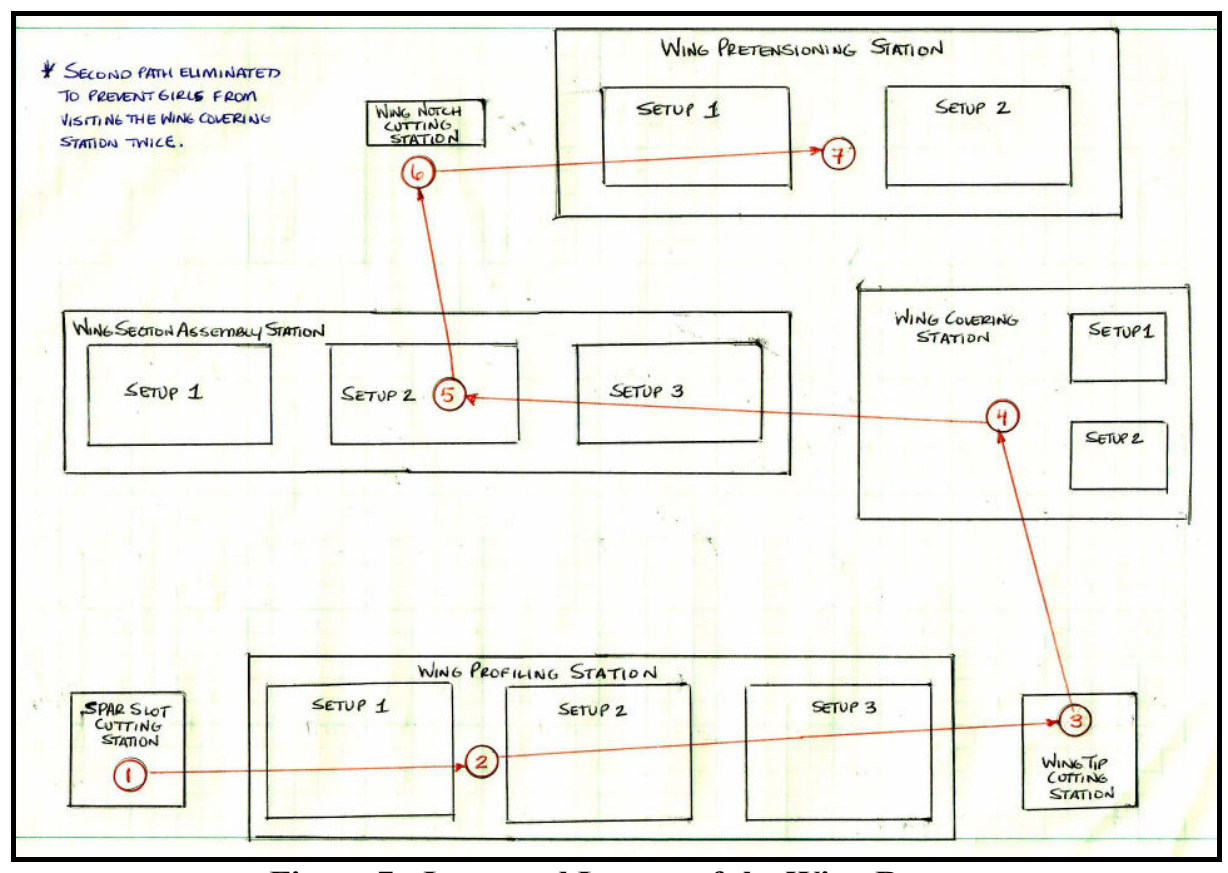

Figure 7: Improved Layout of the Wing Room

As seen in Figure 7, the second dashed path has been eliminated to help prevent confusion, thus simplifying the overall flow a great deal. Also in this diagram, the general setup is much more 
efficient. The bigger fixtures are placed near the walls, not consuming valuable space, and the stations are set up in the order in which they need to be accomplished. The existing flow requires about 75 minutes for a camp participant to construct a set of wings. It is estimated that the new flow will reduce the time of completion to 45-50 minutes. It should be recognized that the estimated time for the new flow has been generated by the camp personnel. The real data will not be available until the next STEPS camp is conducted in the summer of 2006.

\section{Conclusions}

This project, a part of a graduate course, applied classic manufacturing work improvement tools in a non-manufacturing environment. The STEPS program is a noble approach to motivate young girls toward a science and technology career. Because the technical experience of the camp is centered on the plane building activities, it is immensely important that this experience be enjoyable and educational to its participants. This project has deployed classic techniques to analyze the camp's existing activities and processes and has thereby developed a more streamlined, efficient way of accomplishing the same intended goals. Moreover, this project has created an incidental and advantageous learning opportunity for the girls. The participants are exposed to the power of the visual information field, efficient material and tool organization, streamlined process flow and basic ergonomic principles without requiring additional learning sessions. This paper presents a crucial part of the overall suggested improvements for the camp. Many of the proposed changes and reorganizations are already being implemented in preparation for future camps, and the others are under active consideration.

\section{References}

1. Emilani, M. L., “Continuous Personal Improvement,” Journal of Workplace Learning, 1998, v 10, iss. 1, pp 29-36.

2. Stark, C. E., Okado, Y., "Memories without trying: Medial Temporal Lobe Activity associated with Incidental Memory Formation during Recognition," Journal of Neuroscience, 2003, v 23, n 17, pp 6748-53.

3. Kelly, S. W., Burton, A. M., Kato T., Akamatsu S., "Incidental Learning of Real-World Regularities," Psychological Science, 2001, v 12, n 1, pp 86-89.

4. Kundrat, M. E. "Measurement and Methods Improvement for the Grand Valley State University STEPS Camp," submitted to the STEPS Director, GVSU.

5. Greif, Michel. The Visual Factory. Productivity Press, Portland, OR: 1991.

6. Weiss, W. H. "Human Engineering Goals, Minimum Injuries, Maximum Productivity," Production Engineering. 1982.

7. Barnes, R. Motion and Time Study. New York: Wiley, 1980.

8. Konz, S. Work Design. Columbus, OH: Grid, 1979. [1990]

9. "Ergonomics: The Scientific Approach to Making Work Human," International Labour Review. January, 1961. 